\title{
Evaluation of Suitability of Sand Sheet as Sand Filters for Water Treatment, West Al-Sharqat Area, Iraq
}

\author{
Loai Mosa Rawee ${ }^{1}$, Ehab Mohammad Amen ${ }^{1,2}$ and Ektifa Taha Abdulqader ${ }^{1,2}$ \\ ${ }^{1}$ Natural Resources Research Center (NRRC), Tikrit University, Tikrit, Iraq \\ ${ }^{2}$ Applied Geology Department, Science College, Tikrit University, Tikrit, Iraq \\ E-mail: ehab.m86@tu.edu.iq
}

\begin{abstract}
The main objective of this study to assess the properties of Sand sheet in Al- Sharqat City, Iraq, to determine their suitability to be used as water filters. Five stations (1, 2, 3, 4 and 5) were selected according to the variation in the lithological properties, gradation and accessibility to the materials source. Laboratory tests included grain size analysis, water content, specific gravity and chemical analysis. Tests results showed that the moisture content, specific gravity, gypsum content, total dissolved salt, organic matter content, and $\mathrm{pH}$ ranged from 0.90 to $5.48 \%, 2.63$ to $2.66,2.16$ to $14.68 \%, 4.21$ to $20.21,3.81$ to $9.41 \%$, and 7.77 to 8.01 , respectively. The test results vary due to a variety of factors such as sampling depth, secondary gypsum content, and so on. The results showed, according to Indian standard 1993 and Iraqi typical standard (1555 in 2000), the sand sheets in the study area are not appropriate as water filters.
\end{abstract}

Keywords: Sand sheet, Water filtration, Uniformity coefficient, Physiochemical analyses

Water is required in all human activities, whether for agriculture, trade, industry, electricity generation or daily use (Allawai and Ahmed 2019) but water quality is decreasing due to the rapid growth of population, industries as well as other infrastructures. These human activities have a significant effect on the water quality (Kumar and Vipin 2021). Drinking water must be free of chemical and biological contaminants and toxic material (Montana et al 2013). Many of the water sources used by humans contain some vectors of disease that may cause long-term problems. The main problem in most parts of the world is the supply of drinking water to the population as a result of the increase in human population. As the gap between drinking water supply and requirements expand and reach dangerous levels in most parts of the world, it can be a threat to human existence with the reports that the coming wars will be because of water (WHO 2017). Therefore, the scarcity of fresh water can cause serious problem around the world, especially in areas of dry climates with less than $100 \mathrm{~mm}$ of rain. Due to the increase in demand supply needs to meet specific standards. Several purification techniques have been adopted to meet the standards (Ambashta and Sillanpaa 2010). One of the approved methods of water purification is the use of sand filters. Infiltration can be achieved through a sublime barrier that prevents the passage of solid material and allows only liquids to pass without the occurrence of any chemical interaction during the separation process (Jiang et al 2021). The main aim of the filtration process is to remove impurities, solids materials, viruses, bacteria and germs from the water. Normally, a layer of sand, coal, or another granular substance is utilized in public water supply filters (Diwakar et al 2020). Sand proved its adequacy as compared to other materials as a filtering material (Droste and Gehr 2018). Most of the researchers confirmed that the infiltration thickness should be $(60-100 \mathrm{~cm}$, and the effective size range of 0.5 $0.7) \mathrm{mm}$, and uniformity coefficient ranged from 1.2 to $1.7 \mathrm{~mm}$ (Viessman and Hammer 1985). Gravel is used as a supporting layer to prevent sand from getting through during the infiltration process. It should be solid and globular in shape and it should not contain thin and long pieces, and it should not contain mud and glutinous materials. In present study focus is on the studying properties of the sand sheet and their suitability to be used as water filters to make water safe for drinking.

\section{MATERIAL AND METHODS}

Study area: The area is located in Al- Sharqat City, Salahuldin Governorate, north of Iraq, between longitudes

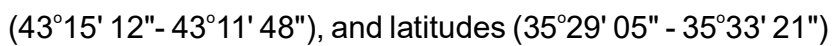
(Fig. 1).

Infiltration and sand filters: The process of infiltration includes the following steps (Khalil 2007):

1. The adhesion of some suspended materials on the sand grains surface and depositing some of them in sand cavities with the help of water meandrous paths which increase the centrifugal force. 
2. Deposition of some solid materials in sand gaps.

3. Sand cavities function as a filter used to prevent suspended material, especially big size.

4. A gelatinous layer of small suspended materials is formed on the sand surface and might have been formed of small living entities that help in preventing suspended material from getting through.

5. The difference in electrical charges between suspended materials and sand grains helps to adhesion these materials to sand grains.

The filters were classified according to filtering speed into two types, rapid sand filters and slow sand filters (Cescon and Jiang 2020).

The first step was to the study area for one month (August- September) to identify the geomorphological effect and the rockoutcrops of the geological formations, and to determine the different field measurements. The second step included a field survey of the study area to determine the locations (where samples were taken at $30-50 \mathrm{~cm}$ in depth) and coordinates of the five stations using GPS, and collecting of sand sheet samples (Fig. 2). Physiochemical test and chemical analyses of samples were performed department of chemical engineering, Tikrit University.

\section{Physical Tests}

Moisture content and specific gravity: It is the ratio of the weight of the water to the total dry weight of the rock (ASTM$D$ 2216) and is calculated according to the following equation. $W \%=M_{\text {wet }}-M_{\text {drn }} / M_{\text {dry }} \times 100=M_{w} / M_{\text {dry }} \times 100 \ldots . .(1)$

Where: $\mathrm{W} \%=$ water content of the soil

$M_{\text {wet }}=$ weight of wet soil,

$M_{\text {dry }}=$ mass of dry soil, obtained at $45^{\circ} \mathrm{C}$ unless otherwise specified

$\mathrm{M}_{\mathrm{w}}=$ mass of water, with oven temperature maintained at $105-110^{\circ} \mathrm{C}$ for 24 hours. Here, $45^{\circ} \mathrm{C}$ is adopted for drying until the weight stabilizes. It was examined in the semi dry season (August-September) according to the American quality (ASTMD 2216 2004) (ITS 2002).

Specific gravity the ratio between the weights of a certain volume of the sample in the air to the weight of the same volume of water was estimated (ASTM- D, 854-02, 2002).

Dry apparent specific gravity (App. GS) $=$ Wd $/($ Wsat-Wsub) .......(2)

This test was carried out on the study area samples (ASTM D 854 2002), Specific weight is considered a criterion is measuring soil volumetric analysis according to the standard classification to define the soil type (Das 1982).

Volumetric analysis: For successful soil analyses and interpretation, soil sampling is essential. First and foremost, a sample must be appropriate for the purpose of the experiment. Second, because the physical and chemical characteristics of soils in fields are varied, taking a representative sample might be challenging (JICA 2014). Samples were test according to the American qualities (ASTM-D 422 2004).

Chemical analyses: Some chemical analyses tests were done to estimate the rate of impurities and harmful material

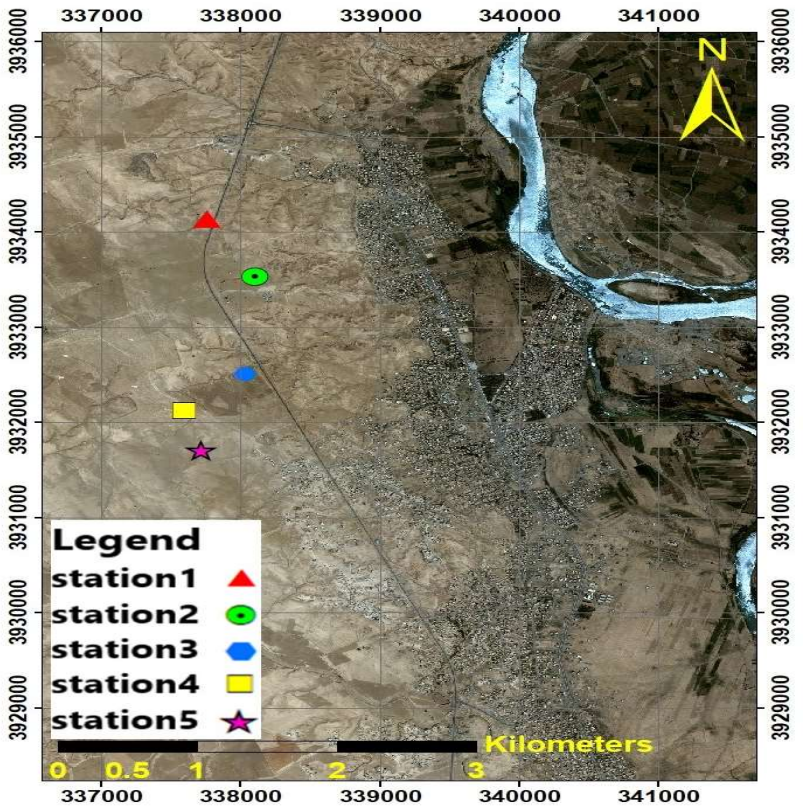

Fig. 1. Location map of the study area

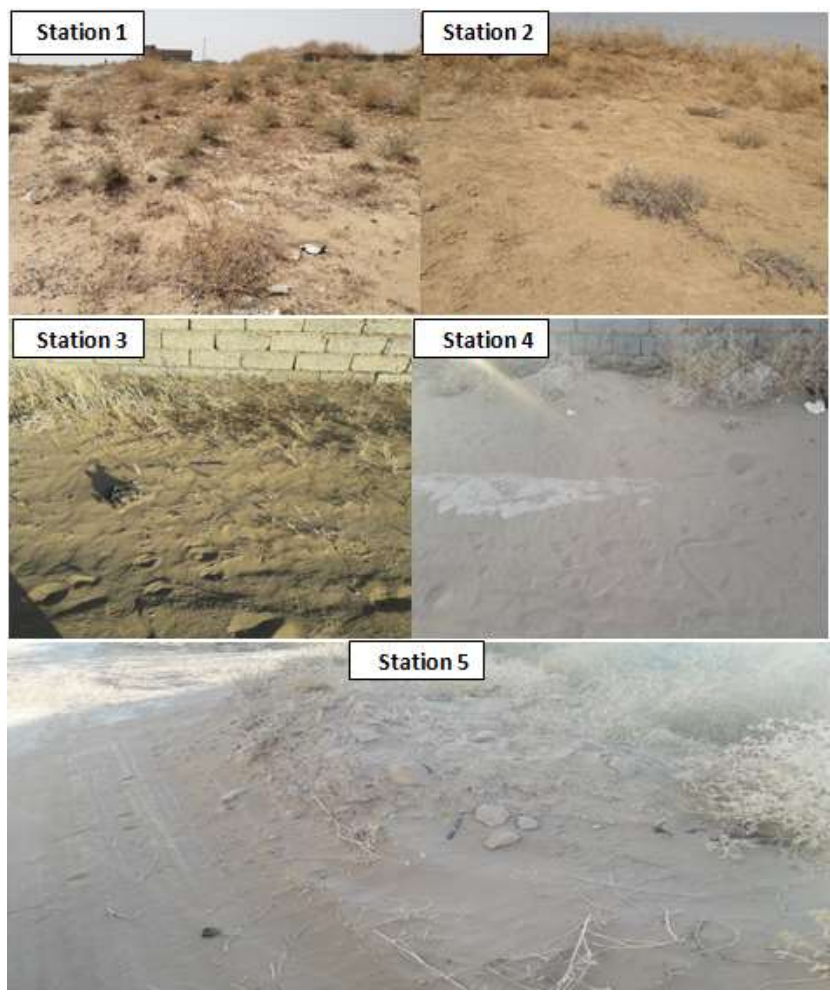

Fig. 2. Sand sheet stations in the study area (sampling from leeward side) 
which affect the architectural structures in which scree is used such as concrete, brick work and water filters (Alfahdawi and Al-nuaymy 2021). These tests included T.D.S., gypsum content, organic I content, and pH (ASTM-D, 42263., 2004).

\section{RESULTS AND DISCUSSION}

Moisture content and specific gravity: Moisture content and specific gravity results obtained from the present study are summarized in Table 1.

Volumetric analysis: The results of the volumetric analysis for all the five investigated stations are presented in Table 2 and Figure 3. The have indicated that all samples of the study area stations are not compatible with the standard measure which is specified for grain gradation of the filtration medium (12-25 mm, and 6-12 mm) mentioned on the ASTM (C136, 2014) and the Iraqi specification 2002 . The poorly graded sand particle where the grain size is no more than $1 \mathrm{~mm}$. When compared the grain size $(1 \mathrm{~mm})$ to the values in the specifications mentioned above, considered a great difference. Moreover, all of the investigated contained mud and alluvium with a varied proportion, which have a negative effect in filtration work. The uniformity coefficient results were as $1.7,2.1,1.9,2$ and 2.3 in the five stations respectively, that doesn't not conform with the typical requirements of the uniformity coefficient (not exceed 1.5) according to the Iraqi specifications (Iraqi standard 2002). The soil specific gravity values ranged from 2.63 to 2.66 .

Chemical analyses: The chemical tests results obtained from this study are summarized in Table 3 . The organic material are incompatible in four stations in accordance with Iraqi specifications (Iraqi standard 2002), but only in station

Table 1. Moisture content and specific gravity of the study area

\begin{tabular}{lcc}
\hline Stations No. & Specific gravity & Moisture content (\%) \\
\hline 1 & 2.65 & 4.39 \\
2 & 2.64 & 2.98 \\
3 & 2.65 & 1.01 \\
4 & 2.66 & 5.48 \\
5 & 2.63 & 0.90 \\
\hline
\end{tabular}

Table 2. Volumetric analysis results of study area precipitations

\begin{tabular}{lccc}
\hline Station & Sand (\%) & Mud (\%) & Uniformity coefficient \\
\hline 1 & 93.6 & 6.40 & 2.3 \\
2 & 97.09 & 2.91 & 2 \\
3 & 97.72 & 2.28 & 1.9 \\
4 & 96.25 & 3.75 & 2.1 \\
5 & 98.33 & 1.67 & 1.7 \\
\hline
\end{tabular}

No. 2 (3.81) does not exceed $5 \%$, thus compatible with that standard. There is incompatibility in gypsum content and the rate of sulfur salts (TDS) solvable in water which affects human health, according to the Iraqi typical specifications
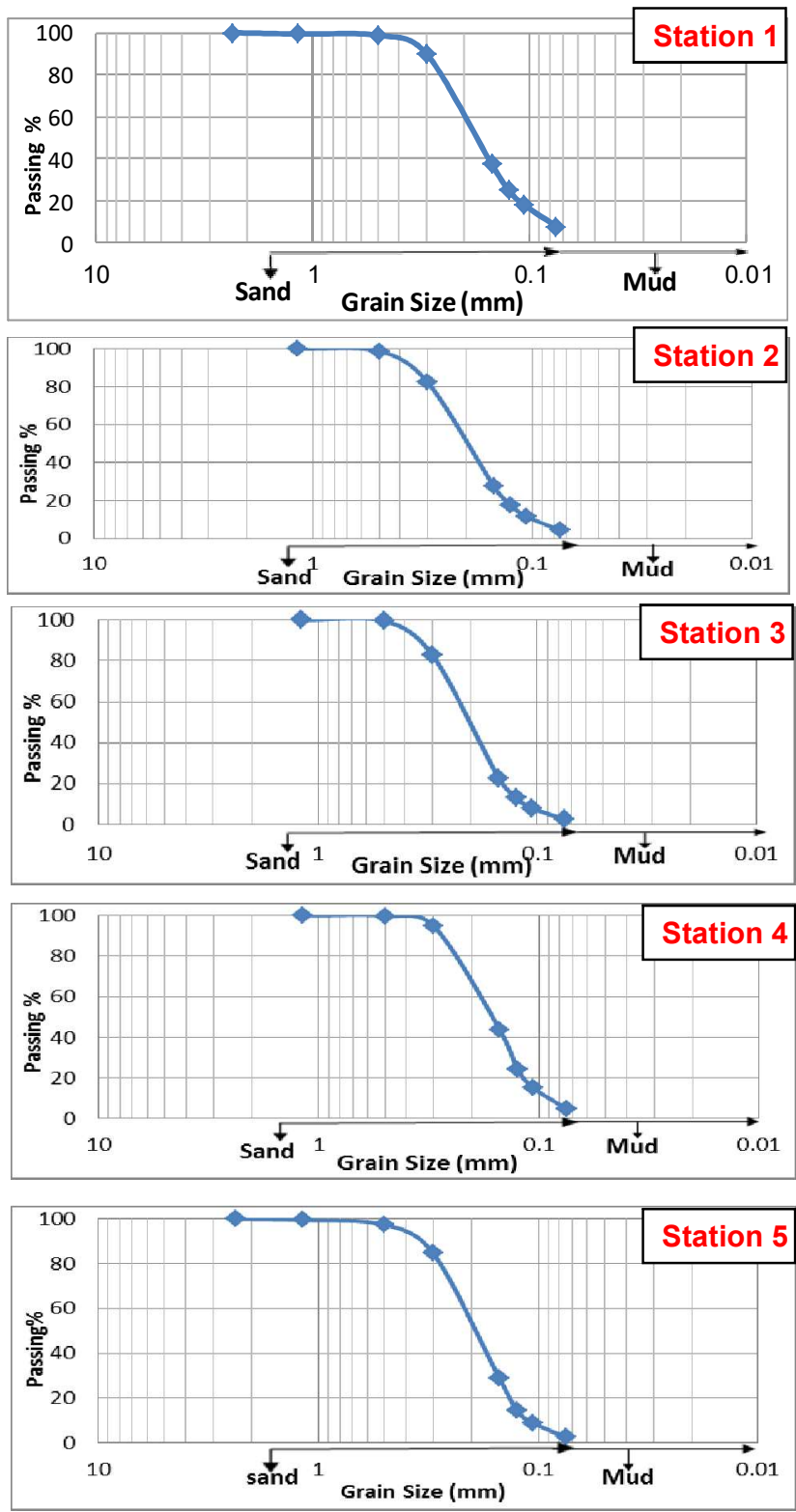

Fig. 3. Volumetric analyses of the study area samples

Table 3. Chemical tests of the study area samples

\begin{tabular}{lcccc}
\hline $\begin{array}{l}\text { Station } \\
\text { no. }\end{array}$ & $\begin{array}{c}\text { Gypsum } \\
\text { content (\%) }\end{array}$ & TDS & $\begin{array}{c}\text { Organic matter } \\
\text { content (\%) }\end{array}$ & $\mathrm{pH}$ \\
\hline 1 & 3.16 & 4.21 & 5.47 & 7.91 \\
2 & 2.14 & 4.77 & 3.81 & 8.00 \\
3 & 14.68 & 20.21 & 7.21 & 7.81 \\
4 & 11.68 & 14.46 & 9.43 & 7.77 \\
5 & 2.16 & 5.21 & 6.05 & 8.01 \\
\hline
\end{tabular}


which should not exceed $1 \%$. The results vary due to a variety of factors such as sampling depth and secondary gypsum content. According to Indian standard (1993) and Iraqi typical standard (1555 in 2000), the sand sheets in the research area are not appropriate as water filters.

\section{CONCLUSIONS}

The grain size analysis results showed abundance in the sand SP type and a decreasing rate of fine types (silt and clay). The chemical tests showed incompatibility with the Iraqi and ASTM standards. The moisture content was low. The results of Volumetric analysis are incompatible with the conditions required in the sand and gravel of water filters. The sand sheet in the study area does not meet the standard specifications thereby; it is not suitable as a water filter. It is recommended conducting a study of the mineral structure of these sand sheets to specify their effects on the surrounding infrastructure and agricultural farms as well as study of geotechnical properties to investigate the property of sand sheet. It is recommended performing other similar scientific studies over many sand dune areas exposed in Iraq.

\section{REFERENCES}

Allawai MF and Ahmed BA 2019. Using GIS and remote sensing techniques to study water quality changes and spectral analysis of Tigris River within Mosul City, North of Iraq. Iraqi Journal of Science 60(10): 2300-2307.

Al-Fahdawi O and Al-nuaymy W 2021. Effect of injecting soils with lime and gypsum by sawdust extract and the wetting and drying cycles on physical properties and phosphorous behavior in the soil. Indian Journal of Ecology 48(4): 1094-1101.

Ambashta R and Sillanpaa M 2010. Water purification using magnetic assistance: A review. Journal of Hazardous Material 180(3): 38-49.

ASTM-C, 136- 969, 2014. Standard Test Method for Sieve Analysis Of Fine And Coarse Aggregates. ASTM International, 100 Barr Harbor Drive, PO Box C700, West Conshohocken, PA 194282959, United States 4(09): 1-5.

ASTM- D 854-02, 2002. Standard Test Methods for Specific Gravity of Soil Solids by Water Pyknic meter. ASTM International, 100 Barr Harbor Drive, PO Box C700, West Conshohocken, PA 19428-2959, United States. 4 (02): 1-7.

Received 26 April, 2021; Accepted 29 November, 2021
ASTM-D 422-63, 2002. Standard Test Method for Particle-Size Analysis of Soils. ASTM International, 100 Barr Harbor Drive, PO Box C700, West Conshohocken, PA 19428-2959, United States. 4(08): 1-8.

ASTM-D 2216-19, 2004. Standard Test Method for Laboratory Determination of Water (Moisture) Content Of Soil \& Rock by Mass. ASTM International, 100 Barr Harbor Drive, PO Box C700, West Conshohocken, PA 19428-2959, United States. 4(08): 1-7.

Cescon A and Jiang J Q 2020. Filtration process and alternative filter media material in water treatment. Water Journal MDPI, 12, 3377. doi:10.3390/w12123377.

Das MB 1982. Soil Mechanics Laboratory Manual. Oxford University Press, New York, USA, 2002.

Diwakar A, Rituja A, Shubhangi G, Suvarna A and Ansari Y 2020. Treatment of Sand Filter Backwash Water from Water Treatment Plant. International Journal of Advanced Science and Technology 29(7): $12130-12137$.

Droste R and Gehr RL 2018. Theory and Practice of Water and Wastewater Treatment John Wiley \& Sons, Inc.992 p.

Flury M 2013. Water infiltration into a frozen soil with simultaneous melting of the frozen layer, Vadose Zone J., 12, vzj2011.0188, https://doi.org/10.2136/vzj2011.0188.

Japan International Cooperation Agency (JICA) 2014. Soil Analysis Manual. NTC International Co., Ltd.TOKYO, Japan, 107 p.

Jiang R, Li T, Liu D,Fu Q, Hou R, Li Q, Cui S and Li M 2021. Soil infiltration characteristics and pore distribution under freezing-thawing conditions, The Cryosphere 15: 21332146.

Khalil A H 2007. The effect of using electrolyte with alum on the of water filterization. Babylon Journal for Human Science 14(4): 473-482 (In Arabic).

Kumar V and Vipin K 2021. Evaluation of Ground Water Quality and Suitability for Irrigation in Nathusari Chopta lock of Sirsa District B (Haryana, India) using Geo-informatics. Indian Journal of Ecology 48(1): 8-12.

Montana M, Camacho A, Serrano I, Devesa R, Matia L and Valles I 2013. Removal of radionuclides in drinking water by membrane treatment using ultrafiltration, reverse osmosis and electrodialysis reversal, Journal of Environmental Radioactivity 125: 86-92.

Iraqi Typical Standard (ITS) No. 1555 2002. Tests of Filters Sand and gravel, the Central Agency for Standardization and Quality Control. P144.

Viessman W and Hammer M 1985. Water Supply and Pollution Control, 4th ed, Harper and Row, New York.

World Health Organization (WHO), 2017. Guidelines for Drinkingwater Quality. 4th ed, incorporating the first addendum. Brazil, $541 \mathrm{p}$. 